\title{
Survey and Analysis of Green Behavior Patterns in Medical Vocational Colleges in China
}

\author{
Xiaomeng Zhang ${ }^{1, a^{*}}$, Tingzhi Wang ${ }^{1, b}$ and Chenjun Wang ${ }^{1, c}$ \\ ${ }^{1}$ Department of Pharmacy, Jiangsu Vocational College of Medicine, Yancheng 224005, China

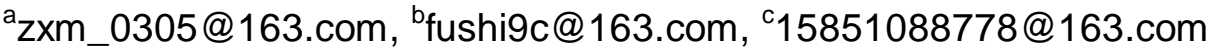 \\ * The corresponding author
}

Keywords: Higher Vocational Colleges; Green Behavior; Questionnaire Survey

\begin{abstract}
Taking Jiangsu Vacation College of Medicine as the research sample, the green behavior pattern of college students was investigated by questionnaire survey. The results show that college students have a high awareness of practicing green behavior, but the implementation is not enough, and there are differences between male and female students. Therefore,education needs to be strengthened and improved relevant policies and regulations to effectively improve green behavior.
\end{abstract}

\section{Introduction}

The green behavior mode of college students refers to the "moderate, rational and positive mental behavior mode which is based on their own actual conditions and adapts to social development"[1]. It requires college students to improve their comprehensive quality in study, life and other aspects[2].

At present, there are 7 academy, 25 professional and more than 6,000 students from all over the country in Jiangsu Vacation College of Medicine, most of them with medicine and health care. A survey of the this college of green behavior pattern can indirectly reflect the health class green behavior status of university students in higher vocational colleges[3], and also can reflect the status of the green behavior of college students.

\section{Research Objects and Methods}

Subjects. Jiangsu Vacation College of Medicine students.

Research Methods. The methods are questionnaire survey and data collection, and interview is assisted[4]. The sample was taken from 7 colleges of the university, and the method of stratified random sampling was adopted.1,000 questionnaires were issued, 992 were returned, 975 were valid, and the effective rate reached $98.3 \%$.

Survey Contents. The survey included knowledge and practice. A total of 17 questions were asked from two aspects: cognition degree of green behavior pattern and specific behavior orientation. The conclusion can reflect the cognition and practice of green behavior style of college students from different angles and to different degrees.

\section{Results and Analysis}

Whether College Students Are Willing to Practice Green Behavior. The survey results on whether college students are willing to practice green behavior patterns are shown in Fig. 1: 


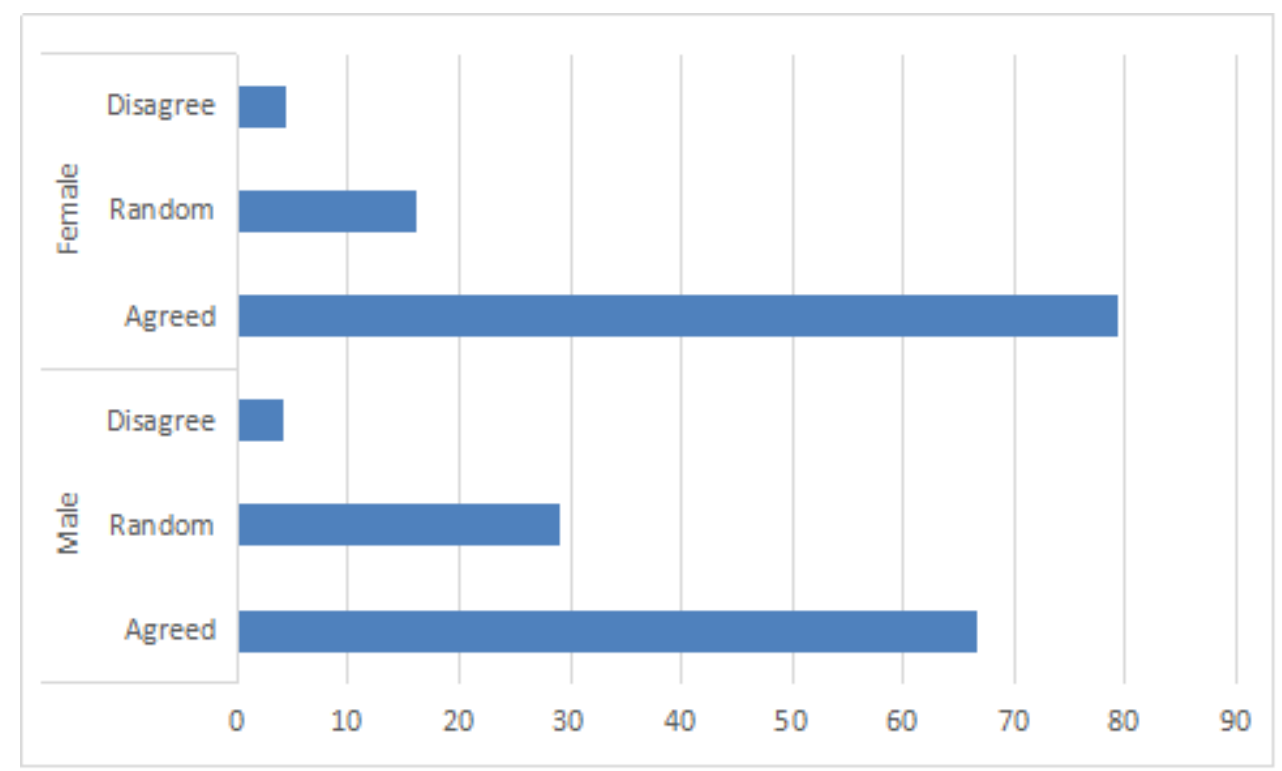

Figure 1. Finite whether college students are willing to practice green behavior (\%)

The survey shows that the majority of students agree to practice green behavior, and only a small number choose to be random. There is almost no students choose disagree. The results show that the willingness of higher vocational college students to practice green behavior is high, which may be related to the increase of education awareness of environmental protection and the willingness of contemporary college students to accept new things.

Investigation and Analysis of Students' Awareness and Practice of Green Behavior Patterns. Using analytic hierarchy process (ahp), 15 questions that can be assigned in the questionnaire were calculated[5]. Efficient consciousness gets 3 points, neutral consciousness gets 2 points, weak consciousness gets 1 point[6]. According to the assignment principle, the average score of students on the four subjects of green behavior pattern awareness and 11 subjects of green behavior pattern practice is shown in table 1 .

Table 1 investigation on students' awareness and practice of green behavior pattern

The average score of

Gender students on four questions concerning green behavior The average score of 11 questions on how to practice green behavior

pattern awareness

\begin{tabular}{cccccccccccccccc}
\hline Male & 1.79 & 2.29 & 2.25 & 2.71 & 2.04 & 2.58 & 2.04 & 2.38 & 1.71 & 2.33 & 2.13 & 2.17 & 1.75 & 1.92 & 2.33 \\
Female & \multirow{2}{*}{1.90} & 2.37 & 2.54 & 2.75 & 2.16 & 2.34 & 2.12 & 2.29 & 1.78 & 2.00 & 1.87 & 2.29 & 1.72 & 2.07 & 2.22 \\
\hline
\end{tabular}

According to SPSS13 analysis, there were significant differences between boys and girls in terms of green behavior pattern cognition and green behavior pattern practice $(\mathrm{P}=0.00002227<0.05)$. This may have something to do with the differences in thinking and behavior between boys and girls, and the specific reasons need further analysis[7].

\section{Conclusions and Suggestions}

Cognition and Practice of Green Behavior Pattern. The investigation shows that students of Jiangsu Vacation College of Medicine have a certain degree of awareness of green behavior and a high awareness of environmental protection. The significance analysis shows that there are significant differences between boys and girls, and the girls are higher than boys in some aspects of cognition and practice. 
Suggestions Based on Survey. Though investigation shows that students have greatly improved in cognition, however, intensify propaganda and explore the effective way of publicity is very necessary, first of all, in order to enlarge the knowledge of propaganda and feeling, and secondly to ensure that the propaganda of normalized. In the way of publicity, new media can be actively explored.

The results show that the students have a certain degree of cognitive behavior way and green environmental protection consciousness, but the practice aspect is not enough, so we should pay attention to the development of environmental protection class practice, and combining propaganda education and practice.

\section{Summary}

This article analyzes the current situation of green behavior of Chinese college students. Through calculation, The cognition degree and differences of green behavior pattern in college students were obtained. The results show that college students have a high level of cognition. At the same time, the conclusion also indicates that the practice of green behavior should be strengthened.

\section{Acknowledgements}

This work was supported by the Jiangsu University Brand Professional Construction Project (PPZY2015A097), the Yancheng Medical Science and Technology Development Project (YK2016048),Jiangsu University Student Practice Innovation Training Project (201812682008Y).

\section{References}

[1] X.Y.Huang, Y.L.Dai and S.Y.Xu.Investigation and Analysis on the Ecological Civilization Awareness and Behavior of Vocational College Students in the West[J].Journal of Sichuan Vocational and Technical College,2015,02:18-22.(In Chinese)

[2] L.J.Li.Empirical Research on Green Consumption Behavior of Vocational College Students[J].Career Horizon,2014,06:137-141.(In Chinese)

[3] L.Li.Experimental Studies on University Students 'Green Consumption Cognition,Consumption Intention and Consumption Behaviour--Based on the Investigation of One University of WuHan[J].Journal of Hubei Polytechnic University(Humanities and Social Sciences), 2014,05:41-44.(In Chinese)

[4] K.Chen and M.Xiao. The investigation and analysis of green consumption cognition, attitude, willingness and behavior of college students -- Based on study of college students in Beijing area[J].Enterprise Economy,2012,03:160-163.(In Chinese)

[5] D.Huang.Research on green education of college students[D].China university of geosciences, 2006.(In Chinese)

[6] S.P.Yang,J.P.Wang and J.L.Zhang.Investigation and analysis of green consumption behavior of college students in western China -- Based on study of shihezi university[J].Journal of Mudanjiang College of Education,2011,04:94-95.(In Chinese)

[7] G.Z.Sun and Q.W.Ye.Empirical Research on Green Consumer Attitude and Behavior of Undergraduates--A sample of Nantong University[J].Journal of Zhejiang Youth College,2011,04:30-34.(In Chinese) 